\title{
LDL physical properties, lipoprotein and Lp(a) levels in acromegalic patients. Effects of octreotide therapy
}

\author{
M. Arosio a,*, G. Sartore ${ }^{\text {b }}$, C.M. Rossi ${ }^{\text {c }}$, G. Casati a , G. Faglia a , E. Manzato ${ }^{\text {, }}$, \\ Italian Multicenter Octreotide Study Group ${ }^{1}$ \\ a Institute of Endocrine Sciences, University of Milano, Ospedale Maggiore IRCCS, via F. Sforza 35, 20122 Milan, Italy \\ ${ }^{\mathrm{b}}$ Department of Internal Medicine, University of Padova, Padova, Italy \\ ${ }^{\mathrm{c}}$ Italfarmaco $\mathrm{SpA}$, Milan, Italy
}

Received 11 March 1999; received in revised form 17 September 1999; accepted 4 October 1999

\begin{abstract}
High vascular morbidity and mortality is associated with acromegaly. The aim of the present study was to assess the effects of octreotide therapy on several known cardiovascular risk factors and to correlate them with octreotide-induced hormonal changes. Lipid levels, LDL particle size distribution as evaluated by single vertical spin density gradient ultracentrifugation, apolipoproteins $\mathrm{AI}$ and B, lipoprotein (a) [Lp(a)] concentrations and apo(a) phenotypes were evaluated in 20 non-diabetic acromegalic patients (6 M, 14 F), with normal thyroid, adrenal and gonadal function, aged 29-66 years. Normal subjects (20), matched for age, sex and BMI served as control for lipid variables. Acromegalic patients were characterized by lower HDL cholesterol (and apoA-I) and by higher $\mathrm{Lp}$ (a) concentrations in comparison to controls. Treatment with octreotide (100 $\mu \mathrm{g}$ t.i.d. for 3 months) led to: an increase in HDL cholesterol (median: $+22 \%$ ), a decrease in LDL cholesterol $(-14 \%)$ and a decrease of the Lp(a) levels (all phenotypes) $(-28 \%)$. The expected decreases of IGF-I levels (median: $-48 \%)$ and 7 -h AUC of GH $(-50 \%)$, insulin $(-40 \%)$, and glucagon $(-20 \%)$ were observed. Only Lp(a) modifications showed a correlation with GH modifications. The study of LDL physical properties showed that acromegalic patients had smaller and/or more dense LDL particles, in comparison with normal controls (relative flotation rate, Rf: $0.40 \pm 0.03$ versus $0.42 \pm 0.02 P<0.05$ ), an alteration that might contribute to the high vascular risk of acromegalic patients. However, the LDL subfraction distribution remained unmodified during octreotide therapy ( Rf $0.39 \pm 0.03$ ). In conclusion, this study shows that in acromegalic patients octreotide treatment is indeed associated with an amelioration of some lipoprotein parameters, i.e. LDL, HDL, and Lp(a) concentrations. However, this treatment has no effect on the small and/or dense LDL particles present in these patients. (C) 2000 Elsevier Science Ireland Ltd. All rights reserved.
\end{abstract}

Keywords: Acromegaly; Octreotide; Somatostatin-analogs; Lipoproteins; Small dense low density lipoprotein; Lipoprotein(a); Apo(a)isoform

\section{Introduction}

Acromegaly is a rare and serious disease associated with an increased cardiovascular mortality [1,2]. For this reason the effects on the cardiovascular risk factors

\footnotetext{
* Corresponding author. Tel.: + 39-02-5464063; fax:. + 39-0255195438.

E-mail address: endosci@mailserver.unimi.it (M. Arosio)

${ }^{1}$ The Italian Multicenter Octreotide Study Group consisted of the following participants: A. Barbarino, Università Cattolica del Sacro Cuore, Rome; S. Cannavò Università di Messina; E. Ciccarelli, Università di Torino; M. Giusti, Università di Genova; S. Squatrito, Università di Catania; G. Tamburrano, Università La Sapienza, Rome.
}

induced by the medical therapy of this disease must be thoroughly evaluated. Octreotide is the most widely investigated and most frequently used somatostatin analogue in the treatment of acromegaly.

Our previous experience, involving a large number of acromegalic patients from all over Italy, seemed to indicate that octreotide, besides decreasing $\mathrm{GH}$ and IGF-I concentrations, had also beneficial effects on lipid levels [3]. In fact, a significant decrease of both total and LDL cholesterol was observed after 3 months of octreotide treatment. However, besides LDL cholesterol concentrations, it is now well recognized that the LDL physical characteristics are important, a predominance of small, dense LDL particles being associated 
with increased vascular risk [4,5]. Recent data suggest that GH excess has a direct effect on LDL subfraction distribution [6]; however, no data exist about the possible effects of therapy, and in particular of octreotide, on LDL size and density.

Increased circulating concentrations of lipoprotein(a) [Lp(a)] may represent an independent risk factor for cardiovascular disease in acromegaly. In fact, although the mechanism by which Lp(a) influences cardiovascular morbidity is largely unknown, several epidemiological studies have shown an association between coronary heart disease incidence and $\mathrm{Lp}(\mathrm{a})$ levels above a threshold concentration of $20-30 \mathrm{mg} / \mathrm{dl}$ [7-9]. Lp(a) shows considerable size variation (from $\approx 300$ to $\approx$ $800 \mathrm{KDa}$ ) among individuals owing to different numbers of cysteine-rich sequences (homologous to plasminogen kringle 4) in the apolipoprotein(a) [apo(a)], resulting in different apo(a) phenotypes. The serum concentrations of $\mathrm{Lp}(\mathrm{a})$ are inversely related to its size, which is genetically determined. Although it is widely accepted that GH has important effects in increasing $\mathrm{Lp}(\mathrm{a})$ concentrations $[10,11]$, it is not known if all apo(a) phenotypes are equally sensitive to $\mathrm{GH}$ modifications.

The aim of the present study was to assess the effects of octreotide therapy on LDL physical properties, and on lipoprotein and $\mathrm{Lp}$ (a) levels (in relation also to the apo(a) phenotype) and to correlate them with hormonal and metabolic changes induced by the therapy. A secondary objective was to verify if acromegaly, non-complicated by diabetes, is associated with modifications of these lipid parameters.

\section{Materials and methods}

\subsection{Design}

Open, multicentric prospective study. The study was approved by the local ethics committees and written informed consent was obtained from all patients.

\subsection{Subjects}

Patients (20) with active acromegaly (as shown by elevated serum IGF-I levels and serum GH not suppressible by glucose load) (14 women, six men), aged 29-66 years (mean $\pm \mathrm{SD}=46 \pm 10$ years), were recruited. Ten patients had been previously submitted to unsuccessful adenomectomy, followed in one case by conventional pituitary radiotherapy and in seven cases by medical therapy with bromocriptine (three patients) and/or somatostatin analogs (seven patients) that was discontinued 1 or more months prior to the start of this study.
Only patients with normal thyroid, adrenal and gonadal functions were admitted to the study, and none of the patients was taking drugs known to influence lipid metabolism, including estrogen-containing drugs or hypoglycaemic agents. Patients with known diabetes mellitus were excluded, and all patients had fasting glucose levels below $110 \mathrm{mg} / \mathrm{dl}$ and normal glycated hemoglobin levels. When considering glucose response to OGTT, however, four patients showed an impaired glucose tolerance according to the criteria of the Expert Committee of the American Diabetes Association [12].

A group of 20 subjects, matched for age, sex and BMI $\left(24 \pm 2 \mathrm{Kg} / \mathrm{m}^{2}\right)$ served as control for lipid variables.

\subsection{Design of the study}

Clinical and biochemical evaluations were performed at baseline and after 3 months of therapy with octreotide (Longastatina ${ }^{\circledR}$, Italfarmaco S.p.A.), $100 \mu \mathrm{g}$ t.i.d. sc under controlled dietary conditions. Pre-treatment studies included the following tests: a 4-h OGTT (75 g orally, to confirm active acromegaly) and a 7-h saline infusion, with a light, standardized meal of about $600 \mathrm{kcal}$ given at $4 \mathrm{~h}$, for $\mathrm{GH}$, insulin, glucagon and glucose assay. IGF-I and lipid parameter measurements were done on two basal samples taken on 2 different days. After 3 months of therapy, the same 7-h study giving octreotide $100 \mu \mathrm{g}$ sc at time 0 and, on a different day, OGTT, giving glucose 2-h after octreotide sc injection, were carried out. Additionally, serum levels of $\mathrm{TSH}$, free T3, free T4, and, in the women, estrogen and progesterone, together with routine laboratory biochemical analysis, were also evaluated.

\subsection{Analytical methods}

All lipid assays were performed at the lipoprotein laboratory in the Department of Internal Medicine, University of Padova.

Cholesterol [13], HDL cholesterol [14], and triglycerides [15] were measured by standard methods. The coefficient of variation $(\mathrm{CV})$, intra-assay and inter-assay, for total cholesterol were 1.0 and $1.2 \%$, respectively, for triglycerides $1.5 \%$ and $2.5 \%$, for $\mathrm{HDL}$ cholesterol $1.2 \%$ and $1.5 \%$. LDL cholesterol levels were calculated using the equation of Friedewald [16].

LDL distribution and flotation properties were evaluated by single vertical spin density gradient ultracentrifugation (SVS-DGUC) using a modification of the method described by Chung et al. [17,18]. One aliquot of $1 \mathrm{ml}$ of plasma adjusted to a density of $1.080 \mathrm{~g} / \mathrm{ml}$ (final volume $4 \mathrm{ml}$ ), was layered underneath $9 \mathrm{ml}$ of a $1.006 \mathrm{~g} / \mathrm{ml} \mathrm{NaCl}$ solution, producing a discontinuous salt gradient in a Beckman VTi 65.1 vertical rotor (Beckman Instruments, Inc., Palo Alto, CA, USA). 
Samples were centrifuged at $65000 \mathrm{rpm}$ for $70 \mathrm{~min}$ (total $\mathrm{t} 2=2.36 \times 1011)$ at $5^{\circ} \mathrm{C}$; the tubes were then fractionated (Fraction Recovery System by Beckman Instruments, Palo Alto, CA, USA) from the bottom at a flow rate of $1.7 \mathrm{ml} / \mathrm{min}$, and $370.35-\mathrm{ml}$ fractions were collected. Total cholesterol was measured in each fraction. The relative flotation rate (Rf), which characterizes LDL peak buoyancy, was obtained by dividing the fraction number containing the LDL-cholesterol peak by the total number of fractions collected. The CV for LDL Rf was $1.1 \%$ intra-assay and $1.7 \%$ inter- assay.

Apolipoproteins AI and B (apo-AI and apo-B) were measured by radial immunodiffusion using standards and plates from Daiichi Pure Chemicals Company. The $\mathrm{CV}$ for apo-AI and apo B were $2.4 \%$ and $1.9 \%$, respectively, intra-assay, and 3.8 and $4.3 \%$, respectively, interassay.

Lp(a), was measured by non competitive sandwichELISA method (Immuno AG, Vienna Austria). Lp(a) glicoprotein phenotype was determined by gel electrophoresis according to Utermann et al. [19] (Immuno AG, Vienna, Austria). The CV, intra-assay and interassay, was 2.9 and $4.1 \%$, respectively.

Hormone measurements were also centralized. Serum GH assay was carried out by IFMA (Delfia, Pharma$\left.\mathrm{cia}^{\circledR}\right)$ at the University of Milano. Plasma IGF-I was measured by RIA after acid-ethanol extraction at the University of Genova [20]. The upper limit of normal IGF-I levels (mean \pm 3 SD) was $366 \mu \mathrm{g} / 1$ for agematched adults. Insulin and glucagon levels were measured by commercial RIA kits (provided by Medgenix Diagnostics, Belgium and DPC, USA, respectively) at the University 'La Sapienza' of Rome. Intra-assay and inter-assay $\mathrm{CV}$ were below 5 and $8 \%$, respectively, for all hormone measurements.

Table 1

Effects of 3 months of octreotide therapy (100 $\mu \mathrm{g}$ t.i.d., sc) on hormonal and metabolic parameters (mean $\pm \mathrm{SD}$ and $\mathrm{AUC} \pm \mathrm{SD}$ )

\begin{tabular}{|c|c|c|c|}
\hline Parameters & Before therapy & Octreotide & $P$ \\
\hline IGF-I (ng/ml) & $665.5 \pm 155$ & $354.3 \pm 206$ & $<0.01$ \\
\hline $\mathrm{GH}(\mu \mathrm{g} / 1)^{\mathrm{a}}$ & $14.3 \pm 31$ & $7.5 \pm 22$ & $<0.01$ \\
\hline $\begin{array}{l}\mathrm{GH}, 7-\mathrm{h} \text { AUC } \\
(\mu \mathrm{g} * \mathrm{~min} / \mathrm{l})\end{array}$ & $6021 \pm 13283$ & $3002 \pm 9089$ & $<0.01$ \\
\hline Insulin $(\mu \mathrm{U} / \mathrm{ml})^{\mathrm{a}}$ & $47.2 \pm 26$ & $29.9 \pm 21$ & $<0.01$ \\
\hline $\begin{array}{c}\text { Insulin, 7-h AUC } \\
(\mu \mathrm{U} * \mathrm{~min} / \mathrm{ml})\end{array}$ & $19718 \pm 11137$ & $11904 \pm 8086$ & $<0.01$ \\
\hline Glucagon $(\mathrm{pgml})^{\mathrm{a}}$ & $72.2 \pm 24$ & $59.6 \pm 25$ & $<0.05$ \\
\hline $\begin{array}{l}\text { Glucagon, 7-h AUC } \\
\quad(\mathrm{pg} * \mathrm{~min} / \mathrm{ml})\end{array}$ & $30018 \pm 10494$ & $24120 \pm 10370$ & $<0.05$ \\
\hline Glucose $(\mathrm{mg} / \mathrm{dl})^{\mathrm{a}}$ & $100.4 \pm 10$ & $112.0 \pm 16$ & $<0.01$ \\
\hline $\begin{array}{l}\text { Glucose, } 7-\mathrm{h} \text { AUC } \\
(\mathrm{mg} * \mathrm{~min} / \mathrm{dl})\end{array}$ & $42184 \pm 4480$ & $47003 \pm 6686$ & $<0.01$ \\
\hline
\end{tabular}

${ }^{a}$ Mean of eight samples taken hourly during 7-h saline infusion.

\subsection{Statistical analysis}

Data with multiple observations for each time $(\mathrm{GH}$, insulin) were quantified by measuring the area under the curves (AUC) using the trapezoidal method. Areas and the mean hormonal and lipid levels were compared using non-parametric statistics (Wilcoxon's signed rank test or Mann-Whitney $U$, as appropriate). Correlation between continuous variables was investigated by regression analysis. All results are expressed as mean \pm $\mathrm{SD}$, unless otherwise stated. Significance is taken as $P<0.05$.

\section{Results}

\subsection{Hormonal and metabolic changes induced by octreotide}

Basal serum GH and IGF-I were elevated in all patients. During octreotide therapy, serum GH levels (mean of eight samples taken hourly during 7-h saline infusion) decreased from $14.3 \pm 31$ to $7.5 \pm 22 \mu \mathrm{g} / 1$ (median: $-60 \%) \quad(P<0.01)$. GH AUC $(7-\mathrm{h})$ was halved $(P<0.01)$. Plasma IGF-I levels (mean of two samples) decreased from $665 \pm 155$ to $354 \pm 206 \mathrm{ng} / \mathrm{ml}$ (median: $-48 \%)$; $(P<0.01)$. Nine patients showed a decrease of mean serum GH levels to below $2 \mu \mathrm{g} / 1$ and normalized IGF-I levels, while one patient normalized IGF-I levels even if mean serum GH concentration was $5.5 \mu \mathrm{g} / 1$.

During octreotide therapy mean insulin and glucagon concentrations significantly decreased, while glucose levels (both pre-prandial and post-prandial), significantly increased (Table 1). Expressed as 7-h AUC, a mean insulin decrease of about $40 \%$, a mean glucagon decrease of about $20 \%$ and a mean glucose increase of $11 \%$ were observed.

As far as the response to a glucose load is concerned, during treatment the blood glucose peak at $2 \mathrm{~h}(4 \mathrm{~h}$ after octreotide administration) was increased in comparison with the baseline test (glucose peak: $194.1 \pm 50$ versus $162.4 \pm 42 \mathrm{mg} / \mathrm{dl}, P<0.01$ ). Insulin release after glucose load was significantly reduced during octreotide therapy with respect to baseline $(129 \pm 89$ versus $155 \pm$ $243 \mu \mathrm{U} / \mathrm{ml}, P<0.01)$.

\subsection{Lipids}

Before treatment, fasting total cholesterol was $207 \pm$ $47 \mathrm{mg} / \mathrm{dl}$, ranging from 128 to $291 \mathrm{mg} / \mathrm{dl}$, and being higher than $200 \mathrm{mg} / \mathrm{dl}$ in ten patients. After treatment, it slightly decreased to $196 \pm 47$ (range from 137 to 305 $\mathrm{mg} / \mathrm{dl}$, median: $-5 . \%$ ), being higher than $200 \mathrm{mg} / \mathrm{dl}$ $(5.2 \mathrm{~mol} / \mathrm{l})$ in seven patients. 
Table 2

Fasting lipid, lipoprotein levels and the relative flotation rate, an index of LDL peak buoyancy, in 20 acromegalic patients before and after 3 months of octreotide therapy (100 $\mu$ g t.i.d., sc) in respect to 20 normal controls ${ }^{\mathrm{a}}$

\begin{tabular}{|c|c|c|c|}
\hline \multirow[t]{2}{*}{ Parameters } & \multirow[t]{2}{*}{ Controls } & \multicolumn{2}{|l|}{ Acromegalics } \\
\hline & & Before therapy & Octreotide \\
\hline $\begin{array}{l}\text { Total cholesterol } \\
\qquad(\mathrm{mg} / \mathrm{dl})\end{array}$ & $207 \pm 42$ & $207 \pm 47$ & $196 \pm 47$ \\
\hline $\begin{array}{l}\text { Total triglycerides } \\
\qquad(\mathrm{mg} / \mathrm{dl})\end{array}$ & $84 \pm 30$ & $98 \pm 94$ & $99 \pm 38$ \\
\hline $\begin{array}{l}\text { LDL cholesterol } \\
\qquad(\mathrm{mg} / \mathrm{dl})\end{array}$ & $125 \pm 40$ & $146 \pm 43^{* *}$ & $125 \pm 40$ \\
\hline $\begin{array}{l}\text { HDL cholesterol } \\
(\mathrm{mg} / \mathrm{dl})\end{array}$ & $65 \pm 13$ & $42 \pm 10^{*, * *}$ & $51 \pm 15^{*}$ \\
\hline Apo-AI (mg/dl) & $175 \pm 25$ & $131 \pm 17^{*}$ & $140 \pm 18^{*}$ \\
\hline Apo-B (mg/dl) & $89 \pm 15$ & $84 \pm 27$ & $79 \pm 26$ \\
\hline $\mathrm{Lp}(\mathrm{a})(\mathrm{mg} / \mathrm{dl})$ & $13 \pm 13$ & $19 \pm 19 * *$ & $14 \pm 13$ \\
\hline $\begin{array}{l}\text { Relative flotation } \\
\text { rate }(\mathrm{Rf})\end{array}$ & $0.42 \pm 0.02$ & $0.40 \pm 0.03 *$ & $0.39 \pm 0.03^{*}$ \\
\hline
\end{tabular}

${ }^{a}$ Data are given as mean \pm SD.

$* P<0.05$ versus controls.

** $P<0.05$ versus octreotide.

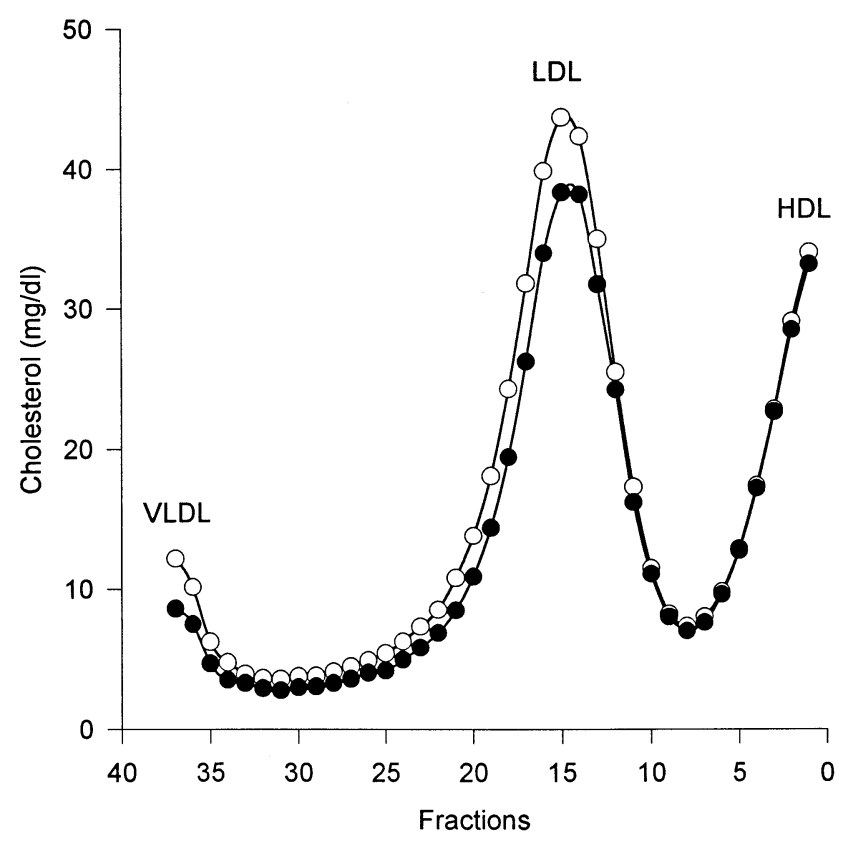

Fig. 1. Vertical spin density gradient ultracentrifugation of plasma lipoproteins in acromegalic patients before (open circles) and during (closed circles) octreotide therapy.

Octreotide therapy induced a significant decrease of LDL cholesterol from $142 \pm 41.1$ to $125 \pm 40 \mathrm{mg} / \mathrm{dl}$ (median: $-14 \%, P<0.05$ ) and a significant increase of HDL cholesterol from $41.7 \pm 9.7$ to $50.6 \pm 15.2 \mathrm{mg} / \mathrm{dl}$ (median: $+22 \%, P<0.05$ ). The number of patients with HDL-cholesterol above $50 \mathrm{mg} / \mathrm{dl}$ increased from 4 to 9 and the number of patients with LDL-cholesterol below $130 \mathrm{mg} / \mathrm{dl}$ increased from 8 to 13 . Triglyceride levels were not modified by octreotide administration. Slight hypertriglyceridemia was present in two patients only, and in both triglyceride levels decreased (from 228 to $206 \mathrm{mg} / \mathrm{dl}$, and from 161 to $115 \mathrm{mg} / \mathrm{dl}$ ).

In respect to normal subjects, there was no significant difference in the pre-treatment or post-treatment levels of total cholesterol and triglycerides. HDL cholesterol levels of untreated acromegalic patients were significantly lower than HDL cholesterol levels of normal subjects (Table 2). The statistical significance was still present when considering post-treatment HDL values.

Single vertical spin-LDL ultracentrifugation showed that the physical characteristics of LDL before and during therapy remained unmodified (Fig. 1). In fact the relative flotation rate, $\mathrm{Rf}$, was $0.40 \pm 0.03$ before octreotide treatment and $0.39 \pm 0.03$ after therapy. In comparison with controls, the LDL particles (both before and during therapy) in acromegalic patients appeared different, with a significantly lower Rf (Table 2).

During therapy apo-AI increased and apo-B decreased in parallel with HDL and LDL changes (Table 2), but the differences failed to reach statistical significance. Just like HDL, apo-AI were significantly lower in acromegalic patients (both before and after therapy) in comparison to normal subjects.

No significant correlations were found between these lipid modifications and GH, IGF-I, insulin, and glucagon changes. Indeed, a greater decrease of LDL was observed in patients who did not normalize $\mathrm{GH}$ and IGF-I concentrations in comparison with patients who did $(-19 \pm 13$ versus $1 \pm 28 \%, P<0.05)$.

$\mathrm{Lp}$ (a) levels were significantly reduced from $19 \pm 19$ to $14 \pm 13 \mathrm{mg} / \mathrm{dl}$ (median: $-28 \%$ ) (Table 2). Apo(a) phenotype distribution in these acromegalic patients is reported in Table 3. All phenotypes were affected by octreotide. Both pre-treatment and post-treatment $\mathrm{Lp}(\mathrm{a})$ concentrations were significantly correlated with pre-treatment $(r=0.6, P<0.01)$ and post-treatment $(r=0.5, P<0.05) \mathrm{GH}$ concentrations respectively, but not with IGF-I or insulin levels. Lp(a) percent decrease observed during therapy, was significantly correlated with GH percent decrease, (Fig. 2). However, this correlation was not statistically significant when one patient who had major modifications of both GH and $\mathrm{Lp}(\mathrm{a})$ is excluded.

\subsection{Other findings}

Thyroid function tests remained within the normal range during the entire study period in all patients. Serum TSH, free T3 and freeT4 were unchanged (TSH: $1.1 \pm 0.7$ versus $1.0 \pm 0.8 \mu \mathrm{U} / \mathrm{ml}$; free $\mathrm{T} 4: 8.4 \pm 5$ versus $8.4 \pm 6$; free $\mathrm{T} 33.5 \pm 1.5$ versus $3.4 \pm 1.4$ ). In 12 women, mean $17 \beta$-estradiol levels were $38.9 \pm 68$ on the day of pre-treatment saline infusion, and $40.7 \pm 57$ 
Table 3

Phenotypes of $\mathrm{Lp}(\mathrm{a})$ : distribution and levels before and after octreotide (mean $\pm \mathrm{SD}$ ) in acromegalic patients

\begin{tabular}{llcc}
\hline $\begin{array}{l}\text { Phenotype } \\
\text { of Apo(a) }\end{array}$ & $\begin{array}{l}\text { No of patients } \\
\text { (\% of total) }\end{array}$ & $\begin{array}{l}\text { Before therapy } \\
\mathrm{mg} / \mathrm{dl}\end{array}$ & $\begin{array}{l}\text { Octreotide } \\
\mathrm{mg} / \mathrm{dl}\end{array}$ \\
\hline S2 & $2(10)$ & $36.1 \pm 28$ & $22.1 \pm 17$ \\
S3 & $7(35)$ & $32.8 \pm 20$ & $25.4 \pm 11$ \\
S4 & $8(40)$ & $2.9 \pm 1$ & $2.3 \pm 1$ \\
S2/S3 & $2(10)$ & $16.2 \pm 10$ & $11.2 \pm 10$ \\
S2/S4 & $1(5)$ & 30.5 & 25.0 \\
\hline
\end{tabular}

the day of control in therapy ( $P$ : NS), progesterone levels non-significantly changed from $3.1 \pm 8.9$ to $0.3 \pm$ 0.3 .

\section{Discussion}

Acromegalic patients were characterized by lower HDL cholesterol levels (and apo-AI) in comparison to controls. Treatment with octreotide led to remarkable changes of the plasma lipoprotein parameters with beneficial effects on several known cardiovascular risk factors: an increase in HDL cholesterol $(+22 \%)$, a decrease in LDL cholesterol $(-14 \%)$ and a decrease of the Lp(a) levels (all phenotypes) being observed. The study of LDL particles confirmed that acromegalic patients had smaller and/or more dense LDL particles in comparison with normal controls. However, the LDL subfraction distribution remained unmodified during octreotide therapy, as we have shown for the first time.

The results on the effects of octreotide on total, LDL, and HDL cholesterol and on triglyceride concentrations are in agreement with the observations previously made in another multicenter Italian study [3]. In fact in that study we found a significant decrease of both total $(-9 \%)$ and LDL cholesterol $(-18 \%)$, and a slight, but not significant increase of HDL $(+4 \%)$ cholesterol. In both studies triglyceride levels decreased only in patients with pre-treatment hypertriglyceridemia (only two cases in the present series).

Only a few other studies report on serum lipid changes in acromegalic patients treated with octreotide [10,21-25]. A decrease of triglyceride levels has been reported [21-24], mostly in patients who had hypertriglyceridemia [22]. The different results with our study may be explained by the facts that in all the mentioned series, about one third of patients had diabetes mellitus (that we have excluded) and also that about $50 \%$ of their patients had moderate hypertriglyceridemia before treatment. No or minor modifications of triglycerides, a significant increase of HDL cholesterol, and a signifi- cant decrease of Lp(a) were observed by Lam et al. [10] and by Wildbrett et al. [25], in agreement with us, after 6 months of octreotide therapy. No significant change in LDL cholesterol levels has been previously reported. As in our study, Lp(a) apart, no correlations between lipid, and hormonal changes have been reported.

It has been shown that $\mathrm{GH}$ is able to increase hepatic LDL receptor expression, resulting in an accelerated elimination rate of the LDL particles and subsequent lowering of LDL cholesterol [26]. The lack of a correlation between hormonal parameters and LDL reduction, suggests that this modification is not due to the $\mathrm{GH}$ metabolic effects. Other factors, including octreotide, might be responsible for the LDL reduction here observed.

The data regarding LDL physical characteristics are of interest. In fact, the LDL physical properties have recently attracted a great deal of attention because of an increased risk of vascular complications associated to the presence of small and/or dense LDL particles in both diabetic and non diabetic patients [4,5].

To our knowledge, only a previous paper by Tan et al. [6] dealt with LDL subfractions distribution in acromegaly, obtaining similar results. According to this author, an increased activity of plasma cholesteryl ester transfer protein (CETP) could contribute to the enhanced formation of small dense LDL particles. Other factors might be involved in modifying the LDL physical properties in acromegalic patients. Both hyperinsulinism and reduced post-heparin lipase activity might be involved in the development of hyperlipidemia in acromegaly [6,27-29]. Hyperinsulinism and insulin resistance are associated with the presence of small and/ or dense LDL particles in diabetic patients [30].

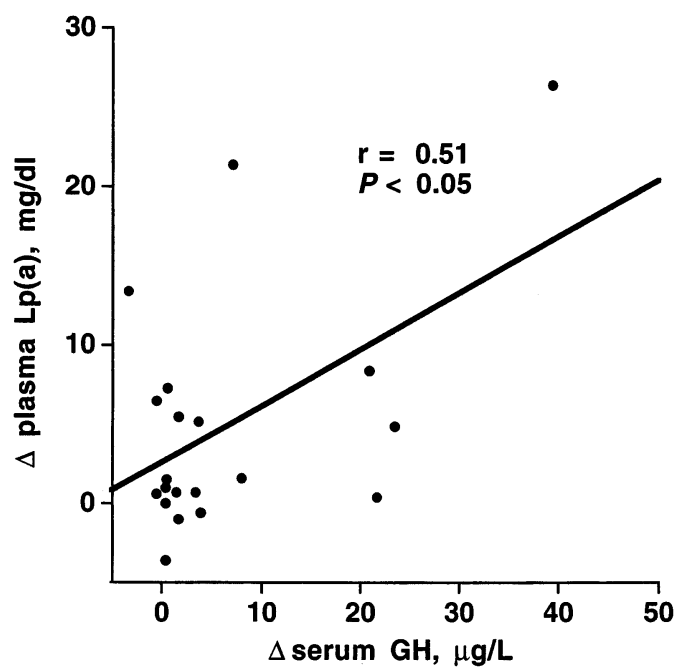

Fig. 2. Correlation between GH and Lp(a) decreases observed during octreotide therapy. 
LDL physical characteristics might also be affected by the hepatic lipase activity. In fact it has been demonstrated that LDL size is inversely related to the hepatic lipase activity [31]. Hepatic lipase is low in acromegalic patients $[6,27]$. Therefore, the presence of small and/or dense LDL particles in acromegalic patients must be determined by factors other than hepatic lipase. Tan et al. [6] indicated that in acromegalic patients GH and HDL are the main determinants of the LDL subclass distribution. The effects of octreotide on CETP and lipases are not known. However, during octreotide treatment we did observe a reduction of GH and an increase of HDL, without any significant effect on LDL physical properties. Octreotide seems to improve insulin sensitivity $[21,32,33]$. A reduced insulin sensitivity is associated with the presence of small and/ or dense LDL particles [30]. The lack of modifications of the LDL physical properties during octreotide therapy is therefore probably due to the balanced results of the modifications in the CETP and hepatic lipase activities, GH levels, HDL levels and insulin sensitivity.

Lp(a) appears to be clearly modulated by GH. The $\mathrm{Lp}$ (a) concentrations in acromegalic patients are usually increased [10] and octreotide treatment resulted in a significant reduction of these concentrations, apparently without any regard to the apo(a) phenotype. We have found, in agreement with Lam [10], a good correlation between $\mathrm{Lp}$ (a) and GH, but not IGF-I, modifications. This lack of a correlation between $\mathrm{Lp}(\mathrm{a})$ and IGF-I levels is consistent with the hypothesis that GH and IGF-I have different, probably opposing effects on Lp(a) levels [34], but also suggests a most important role for $\mathrm{GH}$ in the physiological regulation of $\mathrm{Lp}(\mathrm{a})$ expression in respect to IGF-I.

In conclusion, Lp(a) concentrations are high and directly correlated with GH levels in acromegalic patients. Octreotide therapy decreases Lp(a) levels by decreasing GH concentrations. Low HDL cholesterol levels and a predominance of small and/or dense LDL particles are also present in acromegalic patients and could contribute to the high vascular risk of these patients. Treatment with octreotide is associated with an increase of HDL levels and a decrease of total concentrations of LDL. However, this treatment has no effect on the LDL physical properties.

\section{Acknowledgements}

Octreotide, Longastatina ${ }^{\circledR}$, was kindly supplied by Italfarmaco SpA, Milan, Italy. Italfarmaco also covered the financial burden deriving from hormone assays. We are indebted to Dr B. Chinea for statistical advice, to Prof G Tamburrano (University 'La Sapienza' of Rome) for insulin and glucagon assays and to dr A. Barreca (University of Genova) for IGF-I assay. We gratefully acknowledge Raffaella Marin (University of Padova) for her expert technical assistance in lipid and lipoprotein measurements.

\section{References}

[1] Bates AS, Van't Hoff W, Jones JM, Clayton RN. An audit of outcome of treatment in acromegaly. Qrt J Med 1993;86:2939.

[2] Rajasoorya C, Holdaway IM, Wrightson P, Scott DJ, Ibbertson HK. Determinants of clinical outcome and survival in acromegaly. Clin Endocrinol 1994;41:95-102.

[3] Arosio M, Macchelli S, Rossi CM, et al. Effects of treatment with octreotide in acromegalic patients-a multicenter Italian study. Eur J Endocrinol 1995;133:430-9.

[4] Lamarche B, Tchernof A, Moorjani S, et al. Small, dense low-density lipoprotein particles as predictor of the risk of ischemic heart disease in men. Prospective results from the Québec Cardiovascular Study. Circulation 1997;95:69-75.

[5] Nosadini R, Manzato E, Solini A, et al. Peripheral, rather than hepatic, insulin resistance and atherogenic lipoprotein phenotype predict cardiovascular complications in NIDDM. Eur J Clin Invest 1994;24:258-66.

[6] Tan KCB, Shiu SWM, Janus ED, Lam KSL. LDL subfractions in acromegaly: relation to growth hormone and insulinlike growth factor-I. Atherosclerosis 1997;129:59-65.

[7] Kostner GM, Avogaro P, Cazzolato G, Marth E, Bittolo-Bon G, Quinci GB. Lipoprotein Lp(a) and the risk for myocardial infarction. Atherosclerosis 1981;38:51-61.

[8] Rosengren A, Wilhelmsen L, Eriksson E, Risberg B, Wedel H. Lipoprotein (a) and coronary heart disease in a general population sample of middle-aged men. Brit Med J 1990;301:124850.

[9] Bostom AG, Cupples LA, Jenner JL, et al. Elevated plasma lipoprotein (a) and coronary heart disease in men aged 55 years and younger. A prospective study. JAMA 1996;276:5448.

[10] Lam KSL, Pang RWC, Janus ED, Kung AWC, Wang CCL. Serum apolipoprotein(a) correlates with growth hormone levels in Chinese patients with acromegaly. Atherosclerosis 1993;104:183-8.

[11] Mooser V, Hobbs HH. Lipoprotein(a) and growth hormone: is the puzzle solved? Eur J Endocrinol 1997;137:450-2.

[12] The Expert Committee on the diagnosis and classification of diabetes mellitus. Report of the Expert Committee on the diagnosis and classification of diabetes mellitus. Diabetes Care 1997;20:1183-1197.

[13] Roschlau VP, Bernt E, Gruber W. Enzymatische Bestimmung des Gesamt Cholesterins in Serum. Klin Chem Klin Biochem 1974;12:403-7.

[14] Lipid Research Clinics Program. Lipid and lipoprotein analysis. In: US Department of Health and Human Service, editor. Manual of Laboratory Operations, 2nd edition, Washington DC, 1982: 63-77.

[15] Wahlefeld AW. Triglycerides determination after enzymatic hydrolysis. In: Bergmeyer HU, editor. Methods of Enzymatic Analysis. New York: Academic Press, 1976, 1976:1831-5.

[16] Friedewald WT, Levy RI, Fredrickson DS. Estimation of the concentration of low-density lipoprotein cholesterol in plasma, without use of the preparative ultracentrifuge. Clin Chem 1972;18:499-502.

[17] Chung BH, Wilkinson T, Geer JC, Segrest JP. Preparative and quantitative isolation of plasma lipoproteins: rapid, single discontinuous density gradient ultracentrifugation in a vertical rotor. J Lipid Res 1980;21:284-91. 
[18] Chung BH, Segrest JP, Ray MJ, et al. Single vertical spin density gradient ultracentrifugation. In: Segrest JP, Albers JJ, editors. Methods in Enzymology, vol 128. Plasma Lipoproteins: Preparation, Structure and Molecular Biology. Orlando, FL: Academic Press, 1986:181-209.

[19] Utermann G, Menzel HJ, Kraft HG, Duba HC, Kemmier HG, Seitz C. Lp(a) glycoprotein phenotypes. Inheritance and relation to $\mathrm{Lp}$ (a)-lipoprotein concentrations in plasma. J Clin Invest 1987;80:458-65.

[20] Barreca A, Ciccarelli E, Minuto F, Bruzzi P, Giordano G, Camanni F. Insulin-like growth factor I and daily growth hormone profile in the assessment of active acromegaly. Acta Endocrinol 1989;120:635-9.

[21] James RA, Møller N, Chatterjee S, White M, Kendall-Taylor P. Carbohydrate tolerance and serum lipids in acromegaly before and during treatment with high dose octreotide. Diabetic Med 1991;8:517-23.

[22] Sassolas G, Harris AG, James-Deidier A. Long term effect of incremental doses of the somatostatin analog SMS 201-995 in 58 acromegalic patients. J Clin Endocrinol Metab 1990;71:3917.

[23] Cohen R, Chanson P, Bruckert E, et al. Effects of octreotide on lipid metabolism in acromegaly. Horm Metab Res 1992;24:397400.

[24] Simsolo RB, Ezzat S, Ong JM, Saghizadeh M, Kern PA. Effects of acromegaly treatment and growth hormone on adipose tissue lipoprotein lipase. J Clin Endocrinol Metab 1995;80:3233-8.

[25] Wildbrett J, Hanefeld M, Fucker K, et al. Anomalies of lipoprotein pattern and fibrinolysis in acromegalic patients: relation to growth hormone levels and insulin-like growth factor I. Exp Clin Endocrinol Diabetes 1997;105:331-5.
[26] Rudling M, Norstedt G, Olivecrona H, Reihnér E, Gustafsson $\mathrm{J}$ - $\mathrm{\AA}$, Angelin B. Importance of growth hormone for the induction of hepatic low density lipoprotein receptors. Proc Natl Acad Sci USA 1992;89:6983-7.

[27] Murase T, Yamada N, Ohsawa N, Kosaka K, Morita S, Yoshida $\mathrm{S}$. Decline of postheparin plasma lipoprotein lipase in acromegalic patients. Metabolism 1980;29:666-72.

[28] Fineberg SE, Merimee TJ, Rabinowitz D, Edgar PJ. Insulin secretion in acromegaly. J Clin Endocrinol Metab 1970;30:28892.

[29] Hansen I, Tsalikian E, Beaufrere B, Gerich J, Haymond M, Rizza R. Insulin resistance in acromegaly: defects in both hepatic and extra-hepatic insulin action. Am J Physiol 1986;250:269-73.

[30] Zambon S, Manzato E, Solini A, et al. Lipoprotein abnormalities in non-insulin-dependent diabetic patients with impaired extrahepatic insulin sensitivity, hypertension, and microalbuminuria. Arterioscler Thromb 1994;14:911-7.

[31] Zambon A, Austin MA, Brown BG, Hokanson JE, Brunzell JD. Effect of hepatic lipase on LDL in normal men and those with coronary artery disease. Arterioscler Thromb 1993;13:147-52.

[32] Ho KK, Jenkins AB, Furler SM, Borkman M, Chisholm DJ. Impact of octreotide, a long-acting somatostatin analogue, on glucose tolerance and insulin sensitivity in acromegaly. Clin Endocrinol 1992;36:271-9.

[33] Sato K, Takamatsu K, Hashimoto K. Short-term effects of octreotide on glucose tolerance in patients with acromegaly. Endocrinol J 1995;42:739-45.

[34] Laron Z, Wang XL, Klinger B, Silbergeld A, Wilcken DEL. Insulin-like growth factor-I decreases serum lipoprotein (a) during long-term treatment of patients with Laron syndrome. Metabolism 1996;45:1263-6. 